\title{
Endoscopic transmural necrosectomy for walled-off pancreatic necrosis: A systematic review and meta-analysis
}

\author{
Srinivas R Puli MD ${ }^{1}$, James F Graumlich $M^{2}{ }^{2}$, Smitha R Pamulaparthy MD $^{1}$, Nikhil Kalva MD ${ }^{2}$
}

SR Puli, JF Graumlich, SR Pamulaparthy, N Kalva. Endoscopic transmural necrosectomy for walled-off pancreatic necrosis: A systematic review and meta-analysis. Can J Gastroenterol Hepatol 2014;28(1):50-53.

BACKGROUND: Endoscopic transmural necrosectomy (ETN) is emerging as a viable treatment option for walled-off pancreatic necrosis. This NOTEStype procedure is significantly less invasive than an extensive surgical debridement; however, published data regarding the success of ETN in treating pancreatic necrosis have varied.

OBJECTIVE: To evaluate the published medical literature to determine the success of treating walled-off pancreatic necrosis with ETN.

METHODS: Studies using ETN as a primary mode of therapy to treat organized pancreatic necrosis were selected. Success was defined as resolution of the necrotic cavity proven by radiology. Articles were searched in Medline, PubMed, Ovid journals, CINAH, old Medline, Medline nonindexed citations and the Cochrane controlled trials registry. The summary estimates were expressed as pooled proportions. First, the individual study proportions were transformed into a quantity using Freeman-Tukey variant of the arcsine square root transformed proportion. The pooled proportion was calculated as the back-transform of the weighted mean of the transformed proportions, using inverse arcsine variance weights for the fixed-effects model and DerSimonianLaird weights for the random-effects model. Publication bias was calculated using the Begg-Mazumdar and Harbord bias estimators.

RESULTS: The initial search identified 920 reference articles, of which 129 relevant articles were selected and reviewed. Data were extracted from eight studies $(n=233)$ that met the inclusion criteria. Organization of pancreatic necrosis was determined by computed tomography scan in all of the studies. The mean time of ETN after onset of acute pancreatitis/abdominal pain was seven weeks. The weighted mean size of the necrotic cavity was $12.87 \mathrm{~cm}(95 \%$ CI $10.54 \mathrm{~cm}$ to $15.20 \mathrm{~cm}$ ). The weighted mean number of endoscopic procedures needed to resolve the necrotic cavity was 4.09 (95\% CI 2.31 to 5.87). Pooled proportion of successful resolution of pancreatic necrosis using ETN was $81.84 \%$ (95\% CI $76.73 \%$ to $86.44 \%$ ). The pooled proportion of recurrence in the form of necrotic cavity or pseudocyst after ETN was $10.88 \%$ (95\% CI $7.27 \%$ to $15.11 \%$ ). Complications were noted in $21.33 \%$ (95\% CI $16.40 \%$ to $26.72 \%$ ) of patients and included bleeding, sepsis and perforation. The weighted mean number of days in hospital after ETN was 32.85 days ( $95 \%$ CI 10.50 to 55.20 days). For pancreatic necrosis that did not resolve, surgery had to be performed in $12.98 \%$ (95\% CI $9.05 \%$ to $17.51 \%$ ) of patients. The fixed-effect model was used to report all of the pooled proportions. Estimates calculated using fixedand random-effects models were similar. Test of heterogeneity yielded $\mathrm{P}>0.10$, indicating that the studies could be combined. The publication bias calculated using Begg-Mazumdar bias indicator yielded a Kendall's tau b value of $-0.07(\mathrm{P}=0.72)$ and the same using Harbord bias indicator gave a value of 0.33 ( $95 \% \mathrm{CI}-1.35$ to $2.01 ; \mathrm{P}=0.60$ ). Both of these indicators show that there was no publication bias.

CONCLUSION: The present meta-analysis showed that ETN is safe and effective at treating patients with symptomatic walled-off necrosis. ETN offers the advantage of minimally invasive endoscopic treatment without transabdominal surgery; however, better techniques and equipment are still needed to improve procedural efficiency. Decisions to perform ETN should be made by advanced endoscopists in collaboration with a multidisciplinary team with the facilities and personnel to manage these complex patients.

Key Words: Acute necrotizing pancreatitis; Drainage; Endoscopy; Endosonography; Treatment outcome

\author{
La nécrosectomie transmurale endoscopique en cas de \\ nécrose isolée du pancréas : une analyse systématique et \\ une méta-analyse
}

HISTORIQUE : La nécrosectomie trans murale endoscopique (NTE) émerge comme une possibilité thérapeutique viable de la nécrose isolée du pancréas. Cette intervention de type NOTES est beaucoup moins invasive qu'un débridement chirurgical étendu. Cependant, les données publiées au sujet de la réussite de la NTE dans le traitement de la nécrose du pancréasne sont pas constantes.

OBJECTIF : Évaluer les publications médicales pour déterminer la réussite du traitement de la nécrose isolée du pancréas par NTE.

MÉTHODOLOGIE : Les chercheurs ont sélectionné les études dans lesquelles la NTE était le premier mode de traitement de la nécrose du pancréas. La réussite était définie comme la résolution de la cavité nécrotique, démontrée par radiologie. Les chercheurs ont fouillé dans Medline, PubMed, les revues Ovid, CINAH, l'ancien Medline, les citations non indexées de Medline et le registre d'essais contrôlés Cochrane. Ils ont exprimé les évaluations sommaires en proportions groupées. Ils ont d'abord transformé les proportions des études individuelles en une valeur au moyen de l'écart de Freeman-Tukey sur la proportion transformée par arcsinus-racine carrée. Ils ont calculé la proportion groupée par contretransformation de la moyenne pondérée des proportions transformées, à l'aide des pondérations de variance inversée (arcsinus) pour le modèle à effets fixes et des pondérations de Der Simonian-Laird pour les modèles à effets aléatoires. Ils ont calculé les biais de publication au moyen des corrélateurs de Begg-Mazumdar et de Harbord.

RÉSULTATS : La recherche initiale a permis d'extraire 920 articles de référence, à partir desquels les chercheurs ont sélectionné 129 articles, qu'ils ont analysés. Ils ont extrait les données de huit études $(\mathrm{n}=233)$ qui respectaient les critères d'inclusion. Dans toutes les études, l'organisation de la nécrose du pancréas avait été déterminée par tomodensitométrie. Le délai moyen avant la NTE était de sept semaines après l'apparition de la pancréatite aiguë ou de la douleur abdominale. La cavité nécrotique avait une taille moyenne pondérée de $12,87 \mathrm{~cm}$ ( $95 \%$ IC $10,54 \mathrm{~cm}$ à $15,20 \mathrm{~cm}$ ). Il a fallu une moyenne pondéréede 4,09 interventions endoscopiques ( $95 \%$ IC 2,31 à 5,87) pour résoudre la cavité nécrotique. Les chercheurs ont constaté une proportion groupée de résolution réussie de nécrose pancréatique à l'aide de la NTE de 81,84 \% (95 \% IC 76,73 \% à 86,44 \%) et une proportion groupée de récurrences sous forme de cavité nécrotique ou de pseudokystes après la NTE de 10,88 \% (95 \% IC 7,27 \% à 15,11 \%). Ils ont constaté des complications chez $21,33 \%$ des patients( $(95 \%$ IC $16,40 \%$ à $26,72 \%)$, ce qui incluait des saignements, une septicémie et une perforation. Ils ont relevé une moyenne pondérée de 32,85 jours d'hospitalisation (95 \% IC 10,50 à 55,20) après la NTE. Dans les cas de nécrose du pancréas qui ne se résolvaient pas, il a fallu opérer 12,98 \% des patients ( $95 \%$ IC 9,05\% à 17,51\%). Les chercheurs ont utilisé le modèle à effets fixes pour déclarer toutes les proportions groupées. Les estimations calculées au moyen des modèles à effets fixes et à effets aléatoires étaient similaires. Le test d'hétérogénéité a donné un résultat de $\mathrm{P}>0,10$, ce qui indique la possibilité de combiner les études. Le biais de publication calculé au moyen de l'indicateur de biais de Begg-Mazumdara donné un coefficient tau-b de Kendall de $-0,07 \quad(P=0,72)$ et le même calcul au moyen de l'indicateur de biais de Harbord a donné une valeur de 0,33 (95\% IC $-1,35$ à 2,01; $\mathrm{P}=0,60)$. Ces deux indicateurs révèlent l'absence de biais de publication.

CONCLUSION : D'après la présente méta-analyse, la NTE est sécuritaire et efficace pour traiter les patients présentant une nécrose isolée symptomatique. La NTE confère l'avantage d'un traitement endoscopique minimalement invasif qui évite une chirurgie transabdominale. Toutefois, de meilleures techniques et un meilleur équipement s'imposent pour en améliorer l'efficacité. La décision d'effectuer une NTE devrait être prise par des endoscopistes chevronnés, en collaboration avec une équipe multidisciplinaire disposant des installations et du personnel nécessaires pour soigner ces patients complexes.

${ }^{1}$ Division of Gastroenterology and Hepatology; ${ }^{2}$ Division of General Internal Medicine, University of Illinois College of Medicine at Peoria, Peoria, Illinois, USA Correspondence: Dr Srinivas R Puli, University of Illinois, OSF St Francis Medical Center, 530 Northeast Glen Oaks Avenue, Peoria, Illinois 61637,

USA. Telephone 309-624-9400, fax 309-624-2291, e-mail srinivaspuli@yahoo.com

Received for publication July 19, 2013. Accepted September 15, 2013 
$\mathrm{T}$ he present meta-analysis and systematic review was written in accordance with the proposal for reporting by the QUOROM (Quality of Reporting of Meta-analyses) statement (1). The study design for the present meta-analysis and systematic review conformed to the guidelines of Meta-Analysis of Observational Studies in Epidemiology (MOOSE) study group (2).

Acute pancreatitis (AP) is a mild and self-limiting disease that resolves with conservative medical management in five to seven days, and requires only a brief period of hospitalization. However, acute necrotizing pancreatitis (ANP) develops in approximately 20\% of patients, often complicated by infection, multiorgan dysfunction, sepsis, prolonged hospitalization and even death. AP is now broadly classified as acute interstitial edematous pancreatitis (mild) and ANP (severe) after having undergone revision of the original Atlanta classification (3). Locoregional complications largely including fluid collections that follow an episode of AP have been well recognized in the literature. They can be staged using contrast-enhanced computed tomography (CT) scan and include early ( $<4$ weeks) and late ( $>4$ weeks) complications. Typical early collections include acute peripancreatic fluid collections and acute necrotic collections, and late fluid collections including pancreatic pseudocyst and walled-off pancreatic necrosis (WOPN) (4). Complications of spontaneous rupture, infection with abscess formation, hemorrhage and jaundice is twice as common in untreated patients and is noted to be time dependent, usually after four weeks (5). Traditionally, these fluid collections following ANP were managed surgically with open transperitoneal debridement. This approach has a mortality rate of $11.4 \%$ and is as high as $20.3 \%$ when performed $<4$ weeks (6). Because of the high mortality rate with surgery, the use of minimally invasive (mini-invasive) techniques, such as percutaneous drainage under image guidance and endoscopic necrosectomy, has gained increasing popularity in many centres.

Over the past few years, the technique of mini-invasive endoscopic transluminal necrosectomy (ETN) has evolved from simple aspiration to debridement with nasocystic irrigation. Currently, the technique that is well described uses a linear array echoendoscope with Doppler ultrasound capability. First, the area of interest (transgastric approach) is localized to the pancreas and the peripancreatic tissue. After excluding the vasculature in the vicinity using Doppler ultrasound, a gastrocystic fenestration is created using a 19-gauge needle and samples are sent for pathology. A guide wire is introduced into the necrotic cavity through the fenestration that was previously created and the position is verified under fluoroscopy. The fenestration is now dilated using a controlled radial expansion balloon to create a gastrocystic fistula. Through this newly created fistula, a standard forward-viewing gastroscope is introduced and, using biopsy forceps and snares, the necrotic material is debrided. A stent (usually either plastic or metal) is left in place at the conclusion of the procedure to keep the fistula patent to allow access into the necrotic cavity at a later session. Most patients with severe AP with necrosis complicated by WOPN require multiple sessions to achieve radiographic and clinical success.

Despite the significant progress that has been made over the preceding two decades in the field of mini-invasive treatment of complicated pancreatic fluid collections, the evidence for adaptation into clinical use from various recommendations has been low (7). The aim of the present meta-analysis was to systematically review the published literature and estimate the success and complication rates of ETN or natural orifice transluminal endoscopic surgery (NOTES) in treating WOPN.

\section{METHODS}

Studies investigating ETN for the treatment of organized pancreatic necrosis identified using CT scan were selected. Articles were searched in Medline, PubMed, Ovid journals, EMBASE, Cumulative Index for Nursing \& Allied Health Literature, ACP Journal Club, DARE, International Pharmaceutical Abstracts, OVID Healthstar and the Cochrane Central Register of Controlled Trials (CENTRAL). The search covered 1966 to February 2013. Abstracts were manually searched in the major gastroenterology journals for the past three years. Study authors for the abstracts included in the present analysis were contacted when the required data for the outcome measures could not be determined from the publications. The search terms used were "endoscopy", "endosonography", "acute necrotizing pancreatitis", "drainage" and "treatment outcome". Two authors (SRP and NK) independently searched and extracted the data into an abstraction form. Any differences were resolved by mutual agreement. The agreement aomng reviewers for the collected data was quantified using Cohen's alpha (8).

Clinical trials designed with control and treatment arms can be assessed for quality. A number of criteria have been used to assess study quality (eg, randomization, selection bias of the arms in the study, concealment of allocation and blinding of outcome) $(2,9)$. There is no consensus on how to assess studies designed without a control arm. Hence, these criteria do not apply to studies without a control arm (9).

\section{Statistical methods}

The present meta-analysis was performed by calculating pooled proportions (ie, pooled proportion of patients with study outcome). First, the individual study proportion of study outcome was transformed into a quantity using the Freeman-Tukey variant of the arcsine square root transformed proportion. The pooled proportion is calculated as the back-transform of the weighted mean of the transformed proportions, using inverse arcsine variance weights for the fixed-effects model and DerSimonian-Laird weights for the random-effects model $(10,11)$. Forrest plots were drawn to show the point estimates in each study in relation to the summary pooled estimate. The width of the point estimates in the Forrest plots indicates the assigned weight to that study. The heterogeneity among studies was tested using Cochran's $Q$ test based on inverse variance weights (12). If $\mathrm{P}>0.10$, it rejects the null hypothesis that the studies are heterogeneous. The effect of publication and selection bias on the summary estimates was tested using both the Harbord-Egger bias indicator (13) and Begg-Mazumdar bias indicator (14). Funnel plots were also constructed to evaluate potential publication bias using the standard error $(14,15)$.

\section{RESULTS}

The initial search identified 920 reference articles, of which 129 relevant articles were selected and reviewed. Data were extracted from eight studies $(n=233)$ that met the inclusion criteria $(16-23)$. Figure 1 shows the search results.

The organization of pancreatic necrosis was determined by CT scan in all studies. The mean time of ETN after onset of AP/abdominal pain was seven weeks. The weighted mean size of the necrotic cavity was $12.87 \mathrm{~cm}(95 \%$ CI $10.54 \mathrm{~cm}$ to $15.20 \mathrm{~cm})$. The weighted mean number of endoscopic procedures needed to resolve the necrotic cavity was 4.09 (95\% CI 2.31 to 5.87). The pooled proportion of successful resolution of pancreatic necrosis using ETN was $81.84 \%$ (95\% CI $76.73 \%$ to $86.44 \%)$. Individual study proportion of necrotic cavity resolution is shown in Figure 2. The pooled proportion of recurrence in the form of necrotic cavity or pseudocyst after ETN was $10.88 \%$ (95\% CI $7.27 \%$ to $15.11 \%$ ). Figure 3 shows the same with individual study proportions.

Complications were noted in $21.33 \%$ (95\% CI $16.40 \%$ to $26.72 \%$ ) of patients and included bleeding, sepsis and perforation. The weighted mean number of days in hospital after ETN was 32.85 (95\% CI 10.50 to 55.20 days). For pancreatic necrosis that did not resolve, surgery had to be performed in $12.98 \%$ (95\% CI $9.05 \%$ to $17.51 \%$ ) of patients. The fixed-effect model was used to report all pooled proportions. Estimates calculated using fixed- and random-effects models were similar. Test of heterogeneity yielded $\mathrm{P}>0.10$, indicating that the studies could be combined.

The publication bias calculated using Begg-Mazumdar bias indicator yielded a Kendall's tau b value of $-0.07(\mathrm{P}=0.72)$ and the same using Harbord-Egger bias indicator yielded a value of 0.33 (95\% CI -1.35 to $2.01 ; \mathrm{P}=0.60$ ). Both of these indicators show that there was no publication bias. Also, Figure 4 shows a funnel plot confirming the absence of publication bias. 


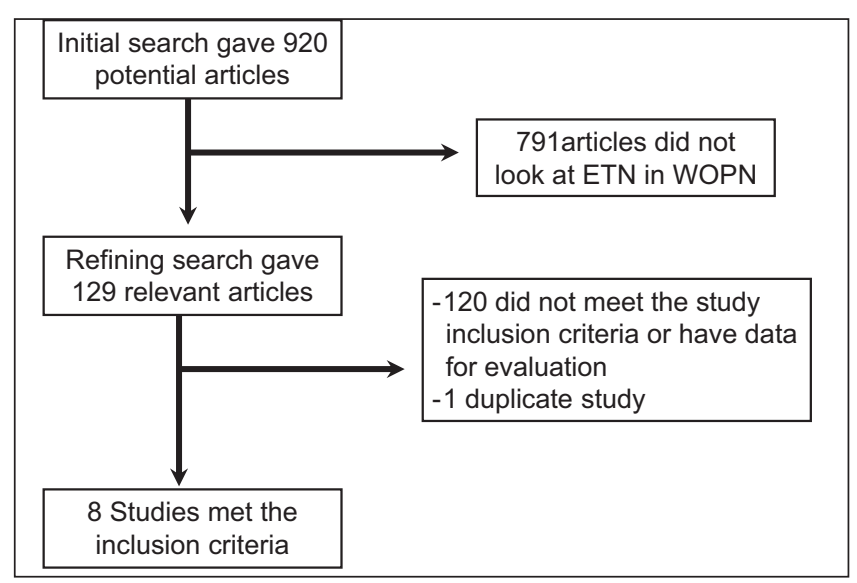

Figure 1) Search results. ETN Endoscopic transluminal necrosectomy; WOPN Walled-off pancreatic necrosis

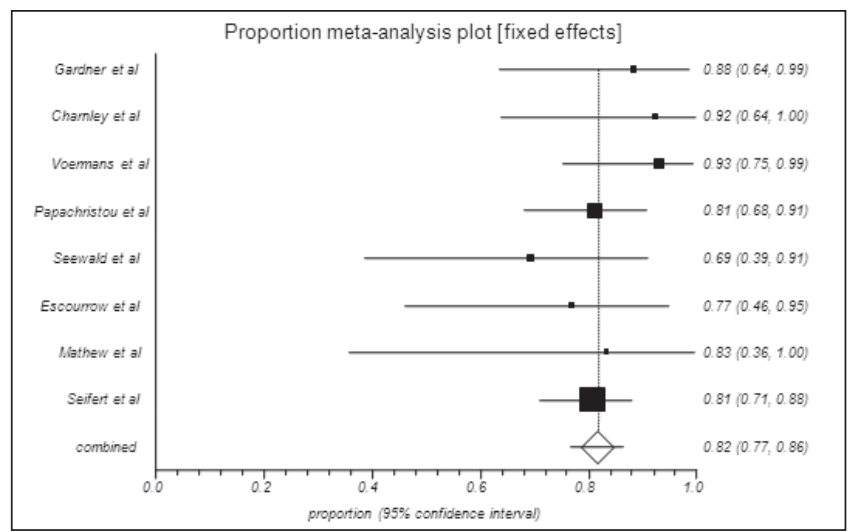

Figure 2) Forrest plot showing the individual study proportion of pancreatic necrosis resolution by endoscopic transluminal necrosectomy

\section{DISCUSSION}

Management of patients with necrotizing pancreatitis remains a challenge, and treatment of both early and late locoregional complications has evolved significantly over the past four decades, from delaying early open necrosectomy in patients with suspected sterile pancreatic necrosis (24) to conservative therapy complemented by aggressive medical management along with mini-invasive therapy in selected patients. It is now recommended that any intervention in the setting of ANP be delayed for four weeks, especially in the absence of infection or symptoms related to sterile necrosis $(25,26)$. This allows the dead and devitalized tissue to be demarcated from the viable tissue to permit adequate necrosectomy and preserve as much of the healthy pancreatic tissue as possible. However, one-third of these patients would require intervention in the early phase of $\mathrm{AP}$ either due to development of infection or progressive organ failure necessitating drainage. It is believed that the mini-invasive therapies, which include percutaneous catheter drainage, ETN and video-assisted retroperitoneal drainage, induce less physiological stress than standard open procedures, which may reduce overall complications. Furthermore, data from randomized controlled studies demonstrated lower levels of serum inflammatory markers, such as interleukin-6, at $24 \mathrm{~h}$ following ETN compared with open procedures at baseline (27). In addition, major complication rates (new-onset multiple organ failure, intraabdominal bleeding, enterocutaneous fistula or pancreatic fistula) in the ETN group were also far fewer (27). Despite showing a significant decrease in complication rates with ETN, a clear mortality benefit compared with open surgery is largely unknown. Despite the limited data comparing traditional open laparotomy and mini-invasive therapies, the trend toward lower overall complication rates has made ETN an attractive option in critically ill patients, especially when infected necrosis is still suspected.

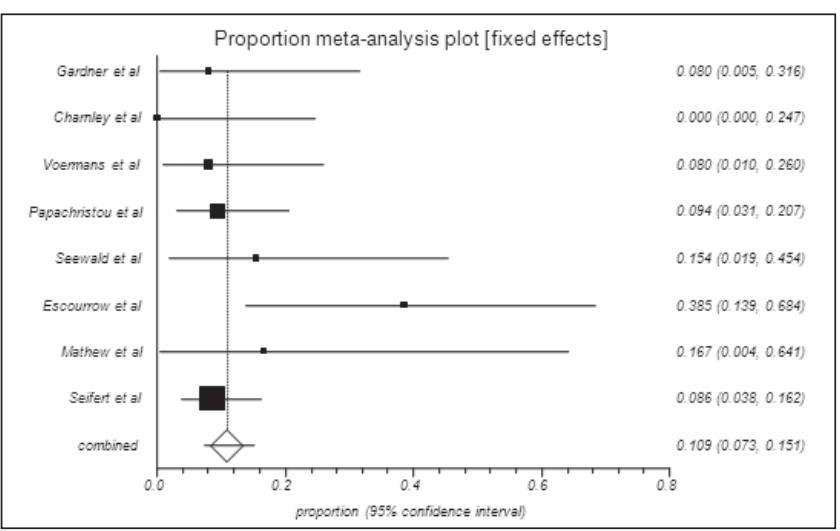

Figure 3) Forrest plot showing the individual study proportion of pancreatic necosectomy recurrence after endoscopic transluminal necrosectomy

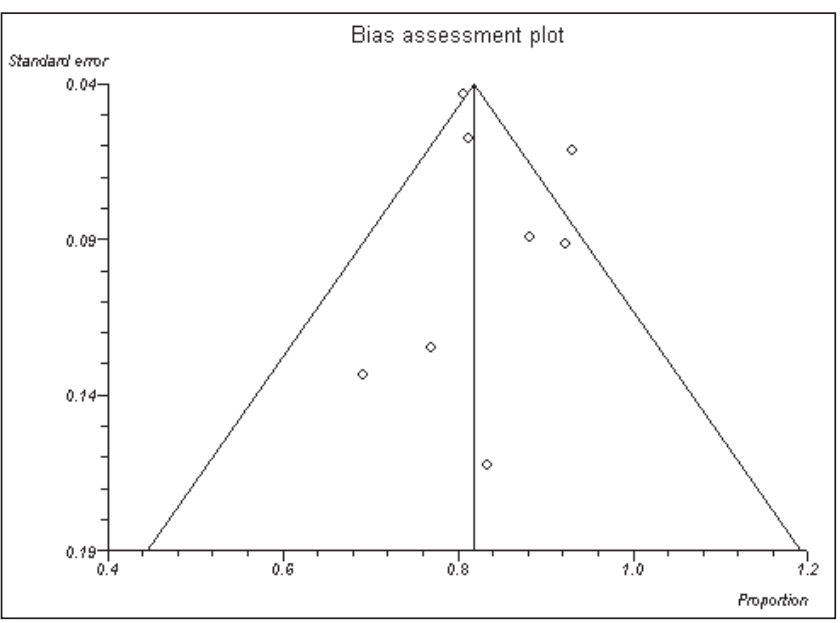

Figure 4) Funnel plot evaluating the effect of publication bias on studies investigating endoscopic transluminal necrosectomy for walled-off pancreatic necrosis

The approach to treatment in patients with necrotic fluid collections in the late phase is controversial. Whether to intervene surgically is dictated by the patient's clinical condition (ie, presence of or suspected infection, and symptoms such as mechanical obstruction, anorexia, continued pain and progressive malnutrition). Previously published literature also supports conservative therapy for asymptomatic and small fluid collections because aspiration increases the risk for introduction of an iatrogenic infection (28). Necrosectomy, either traditional or using a mini-invasive approach, becomes necessary in large, organized necrosis because they are symptomatic, harbour infection or become infected at some point during episodes of pancreatitis.

In the current systematic review and meta-analysis, we sought to determine the role of ETN for the treatment of necrotizing pancreatitis with late complications, such as WOPN, which could be sterile or harbour infection. In the pooled analysis, ETN appeared to be an efficacious, mini-invasive procedure, with a radiographic success rate of $81.8 \%$. The procedure was also safe, with major complications rates of bleeding, organ perforation and sepsis determined to be $21.3 \%$. Patients with WOPN also require prolonged hospitalization with utilization of substantial health care resources adding to costs. In the current study, in patients who were successfully treated with ETN, the weighted average duration of hospital stay was 32 days, with a mean of four procedures per patient. Despite a favourable pooled radiographic success rate, surgery for a nonresolving necrotic cavity could not be avoided and it appears that studies involving the sickest patients confirmed the need for surgery.

One limitation of the current meta-analysis was the inclusion of studies that were mostly retrospective case series. The number of 
patients included in most of the studies were too few in number and were unselected to draw comparative conclusions with alternative operative modalities. There were also some technical differences, with some series using ETN without the aid of endoscopic ultrasound to identify an appropriate transmural puncture site. Furthermore, details of the the necrosectomy procedure evolved over time, with use of larger stents to facilitate drainage and direct necrosectomy once the cavity was accessed. Despite the success rate with ETN reported above, approximately $13 \%$ of the pooled patients required surgical intervention for recurrence or nonresolution. More studies are needed to better risk stratify patients who are at risk for radiographic failure, and would need additional surgery and experience complications as technological advancements in endoscopic therapy for pancreatic surgery evolve. We could only speculate that patients at risk for endoscopic failure have peripancreatic necrosis that extends into the paracolic gutter because of lack of continuity with central necrosis. Papachristou et al (19) reported on a cohort of patients with large WOPN $(>15 \mathrm{~cm})$ and extension into the paracolic gutter who were at risk for failure; however, size alone was not considered to be a risk for failure (19). Patients with the above WOPN characteristics may be best served using a multimodal approach that includes a combination of ETN, percutaneous catheter drainage and video-assisted retroperitoneal drainage.

Studies with statistically significant positive results tend to be published and cited. Additionally, smaller studies may show larger treatment effects compared with larger studies. This publication and selection bias may affect the summary estimates. This bias can be estimated using Egger bias indicators and the construction of funnel plots, whose shape can be affected by bias. In the present meta-analysis and systematic review, bias calculations using both Egger (13) and Begg-Mazumdar (14) bias indicators showed no statistically significant bias. Furthermore, analysis using funnel plots showed no significant publication bias among the studies included in the present analysis.

\section{CONCLUSION}

ETN is an effective and safe alternative to open surgical drainage, with acceptable complications and offering the advantage of miniinvasive therapy for treating patients with symptomatic WOPN. In patients who do not demonstrate radiological response to ETN, surgery would be necessary. We speculate that it would be more practical to have a model of 'step-up endoscopic' approach. Wellconducted, multicentre randomized controlled studies are warranted to assess how step-up ETN compares with surgery in the management of these complicated patients and to identify those at risk for complications and treatment failure. Given the complex nature of symptomatic necrotizing pancreatitis and paucity of comparative studies, we suggest a multidisciplinary approach, ideally at centres with expertise in advanced endoscopy, surgery and radiology, with consideration of ETN in carefully selected patients.

DISCLOSURES: The authors report no grant support, financial disclosures or conflicts of interest.

\section{REFERENCES}

1. Moher D, Cook DJ, Eastwood S, Olkin I, Rennie D, Stroup DF. Improving the quality of reports of meta-analyses of randomised controlled trials: The QUOROM statement. Quality of Reporting of Meta-analyses. Lancet 1999;354:1896-900.

2. Stroup DF, Berlin JA, Morton SC, et al. Meta-analysis of observational studies in epidemiology: A proposal for reporting. Meta-analysis Of Observational Studies in Epidemiology (MOOSE) group. JAMA 2000;283:2008-12.

3. Banks PA, Bollen TL, Dervenis C, et al. Classification of acute pancreatitis - 2012: Revision of the Atlanta classification and definitions by international consensus. Gut 2013;62:102-11.

4. Thoeni RF. The revised Atlanta classification of acute pancreatitis: Its importance for the radiologist and its effect on treatment. Radiology 2012;262:751-64.

5. Bradley EL, Clements JL Jr, Gonzalez AC. The natural history of pancreatic pseudocysts: A unified concept of management. Am J Surg 1979;137:135-41.

6. Rodriguez JR, Razo AO, Targarona J, et al. Debridement and closed packing for sterile or infected necrotizing pancreatitis: Insights into indications and outcomes in 167 patients. Ann Surg 2008;247:294-9.

7. Banks PA, Freeman ML, Practice Parameters Committee of the American College of Gastroenterology. Practice guidelines in acute pancreatitis. Am J Gastroenterol 2006;101:2379-400.

8. Brennan P, Silman A. Statistical methods for assessing observer variability in clinical measures. BMJ 1992;304:1491-4.

9. Jadad AR, Moore RA, Carroll D, et al. Assessing the quality of reports of randomized clinical trials: Is blinding necessary? Control Clin Trials 1996;17:1-12.

10. Stuart A, Ord JK. Kendall's Advanced Theory of Statistics, 6th edn. London: Edward Arnold, 1994.

11. DerSimonian R, Laird N. Meta-analysis in clinical trials. Control Clin Trials 1986;7:177-88.

12. Deeks JJ. Systematic reviews of evaluations of diagnostic and screening tests. In: Systematic Reviews in Health Care. London: BMJ Publishing Group 2001;2008:248-82.

13. Harbord RM, Egger M, Sterne JA. A modified test for small-study effects in meta-analyses of controlled trials with binary endpoints. Stat Med 2006;25:3443-57.

14. Begg CB, Mazumdar M. Operating characteristics of a rank correlation test for publication bias. Biometrics 1994;50:1088-101.

15. Sterne JA, Egger M, Smith GD. Investigating and dealing with publication and other biases in meta-analysis. BMJ 2001;323:101-5.
16. Gardner TB, Chahal P, Papachristou GI, et al. A comparison of direct endoscopic necrosectomy with transmural endoscopic drainage for the treatment of walled-off pancreatic necrosis. Gastrointest Endosc 2009;69:1085-94.

17. Charnley RM, Lochan R, Gray H, O'Sullivan CB, Scott J, Oppong KE. Endoscopic necrosectomy as primary therapy in the management of infected pancreatic necrosis. Endoscopy 2006;38:925-8.

18. Voermans RP, Veldkamp MC, Rauws EA, Bruno MJ, Fockens P. Endoscopic transmural debridement of symptomatic organized pancreatic necrosis (with videos). Gastrointest Endosc 2007;66:909-16.

19. Papachristou GI, Takahashi N, Chahal P, Sarr MG, Baron TH. Peroral endoscopic drainage/debridement of walled-off pancreatic necrosis. Ann Surg 2007;245:943-51.

20. Seewald S, Groth S, Omar S, et al. Aggressive endoscopic therapy for pancreatic necrosis and pancreatic abscess: A new safe and effective treatment algorithm (videos). Gastrointest Endosc 2005;62:92-100.

21. Escourrou J, Shehab H, Buscail L, et al. Peroral transgastric/ transduodenal necrosectomy: Success in the treatment of infected pancreatic necrosis. Ann Surg 2008;248:1074-80.

22. Mathew A, Biswas A, Meitz KP. Endoscopic necrosectomy as primary treatment for infected peripancreatic fluid collections (with video). Gastrointest Endosc 2008;68:776-82.

23. Seifert H, Biermer M, Schmitt W, et al. Transluminal endoscopic necrosectomy after acute pancreatitis: A multicentre study with long-term follow-up (the GEPARD study). Gut 2009;58:1260-6.

24. Bradley EL III, Allen K. A prospective longitudinal study of observation versus surgical intervention in the management of necrotizing pancreatitis. Am J Surg 1991;161:19,24; discussion 24-5.

25. Uhl W, Warshaw A, Imrie C, et al. IAP guidelines for the surgical management of acute pancreatitis. Pancreatology 2002;2:565-73.

26. Besselink MG, Verwer TJ, Schoenmaeckers EJ, et al. Timing of surgical intervention in necrotizing pancreatitis. Arch Surg 2007;142:1194-201.

27. Bakker OJ, van Santvoort HC, van Brunschot S, et al. Endoscopic transgastric vs surgical necrosectomy for infected necrotizing pancreatitis: A randomized trial. JAMA 2012;307:1053-61.

28. Zerem E, Imamovic G, Omerovic S, Imsirovic B. Randomized controlled trial on sterile fluid collections management in acute pancreatitis: Should they be removed? Surg Endosc 2009;23:2770-7. 


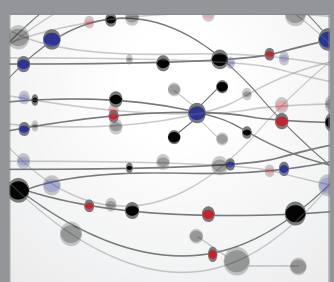

The Scientific World Journal
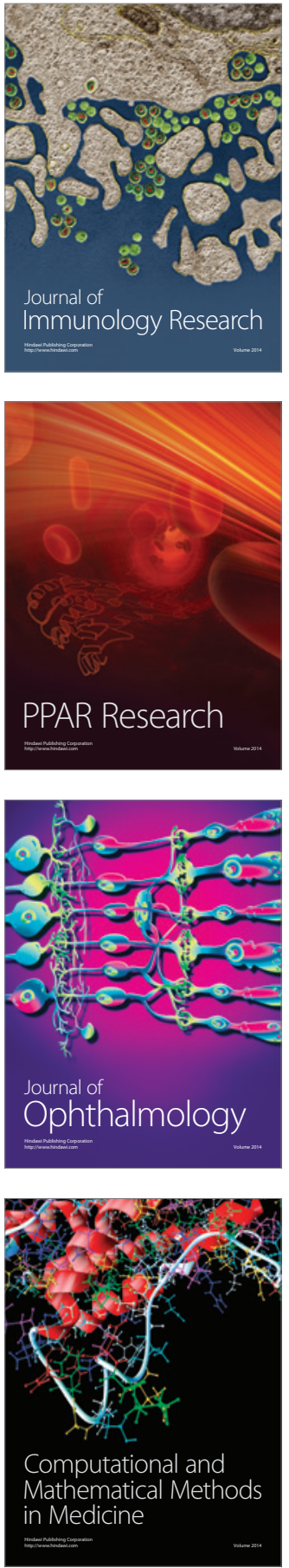

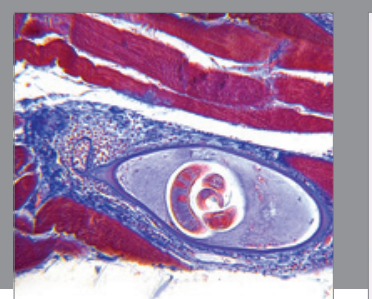

Gastroenterology Research and Practice

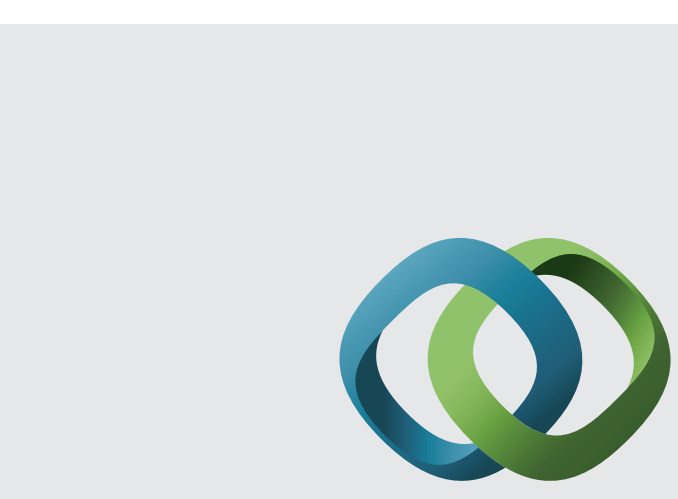

\section{Hindawi}

Submit your manuscripts at

http://www.hindawi.com
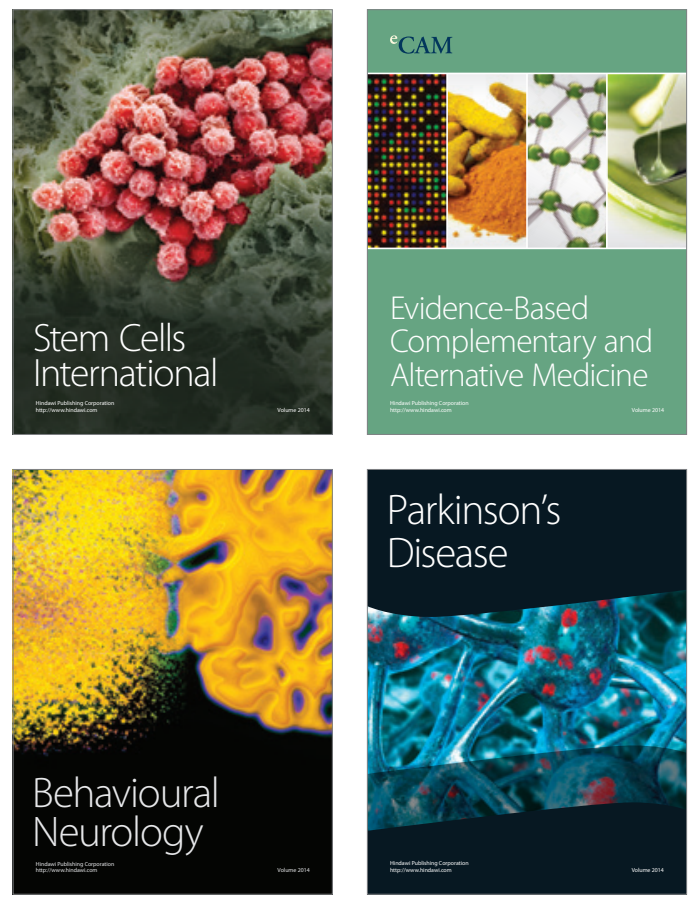
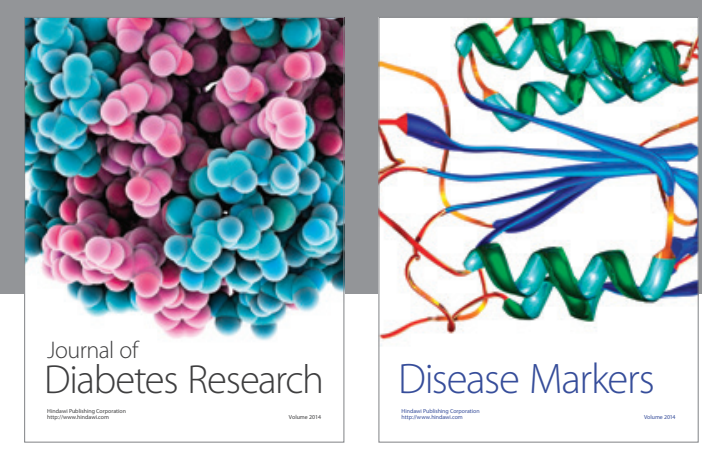

Disease Markers
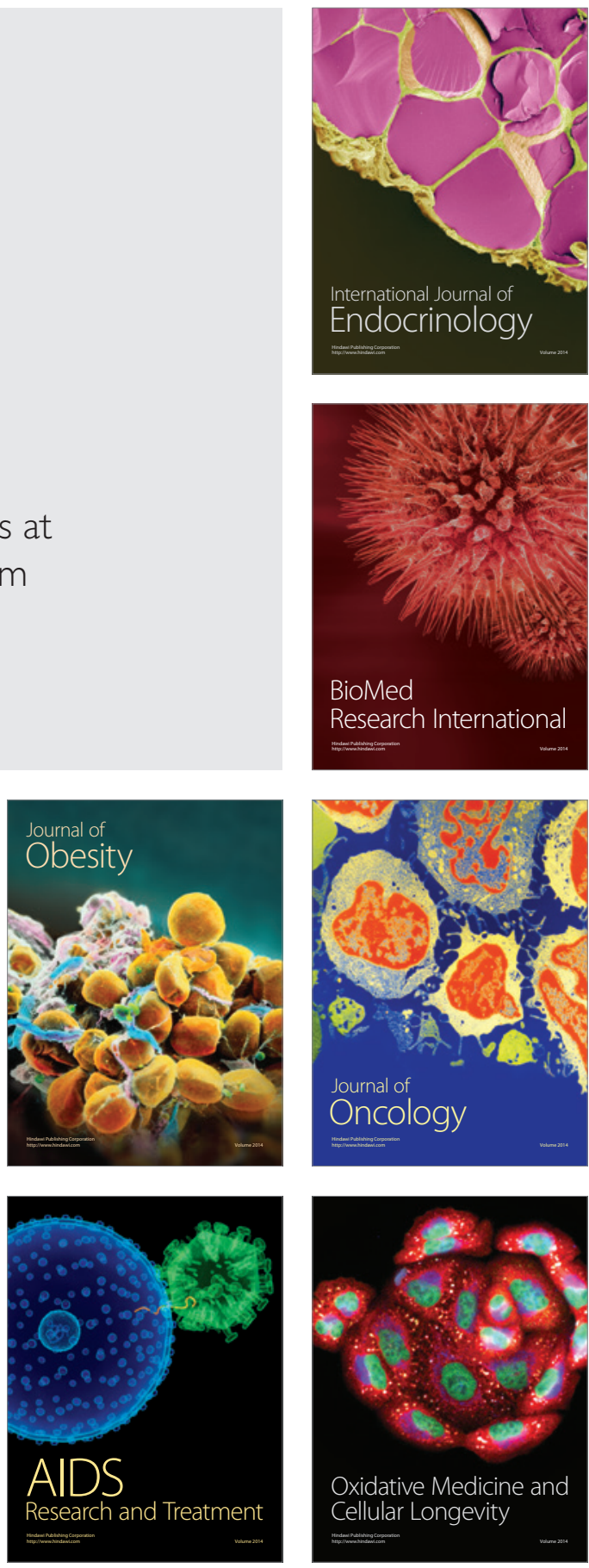